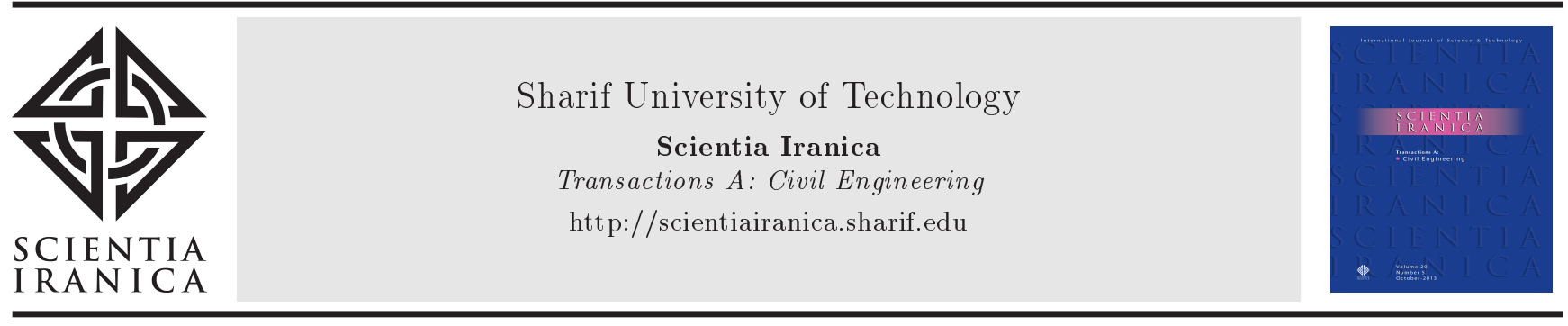

\title{
Engineering properties of sand reinforced with plastic waste
}

\author{
B. Ta'negonbadi, R. Noorzad*, and P. Shakery \\ Faculty of Civil Engineering, Babol Noshirvani University of Technology, Babol, Iran. \\ Received 30 May 2020; received in revised form 24 July 2020; accepted 3 October 2020
}

\author{
KEYWORDS \\ Sand reinforcement; \\ Shear strength; \\ Plastic waste; \\ Fiber-shaped plastic; \\ Triaxial compression \\ test.
}

\begin{abstract}
A series of triaxial compression tests were performed in an attempt to evaluate the benefits of plastic wastes and investigate the engineering properties of sand reinforced with such materials. In this research, the effects of the contents $(0,0.25,0.5,0.75$, and $1 \%$ of the dry weight of sand) and types of plastic wastes (Poly-Ethylene Terephthalate (PET) and Poly-Propylene (PP) fibers) as well as the confining pressures (50, 100, and 200 $\mathrm{kPa}$ ) on the sand behavior in Babolsar, Iran were investigated. The values for deformation modulus (up to $84 \%$ ), peak (up to 7 times of the unreinforced sand), and steady state shear strength increased upon reinforcement. Moreover, axial strain at failure for fiber-reinforced sand increased up to 1.5 times its unreinforced counterpart (from $3.36 \%$ to $8.53 \%$ for $1 \%$ $\mathrm{PP}$ usage at confining pressure of $50 \mathrm{kPa}$ ). Generally, it can be concluded that using plastic wastes in the sand would result in low-cost soil reinforcement and a reduction in the disposal problem of these kinds of wastes.
\end{abstract}

(C) 2021 Sharif University of Technology. All rights reserved.

\section{Introduction}

Inaccessibility to lands with fair bearing capacity for construction has turned into a challenging problem that compels engineers to use local lands. In such cases, soil improvement techniques such as soil reinforcement and soil stabilization behaved satisfactorily in many conditions. Soil reinforcement is performed using different methods and materials such as different types of geosynthetics and fibers.

There are at least two advantages to use the randomly distributed fiber as the reinforcement. First, discrete fibers are simply added and mixed randomly with soil as cement, lime, or other additives. Second, randomly distributed fibers restrict the potential

*. Corresponding author. Tel.: +98 113527837r

E-mail addresses: bahram.gonbadi@gmail.com (B.

Ta'negonbadi); rn0864@gmail.com, rnoorzad@nit.ac.ir (R.

Noorzad); P_shakery@yahoo.com (P. Shakery)

doi: $10.24200 /$ sci.2020.55886.4448 planes of weakness that can develop parallel to the oriented reinforcement [1-4].

Nowadays, driven by the urgency to deal with environmental and economic problems, researchers emphasize the need to use alternative materials suitable for better design characteristics. One possible way to reuse these wastes is to convert them into materials for soil reinforcement and construction applications such as highway base material and backfill of retaining walls. The soil reinforced by waste plastic strip can be used in embankment/road construction, thus significantly reducing cost and ensuring safe disposal of these waste materials in an environmentally friendly manner [5-9]. In this regard, a number of researchers have focused on finding appropriate ways of reusing waste materials. Plastic wastes are usually highly strong materials with less reactivity with acids and alkalis. This type of waste is not biodegradable and may remain unchanged for years and cause environmental pollution $[6,7]$.

Using plastic wastes such as tire shreds for improving the mechanical properties of soil dates back to the year 1990. Numerous researchers have investigated 
the engineering properties of plastic waste reinforced soils [2,4, 6-18]. The idea of incorporating other plastic wastes into the soil was first proposed by Benson and Khire [19]. They utilized translucent HDPE milk jugs cut into strips as reinforcing materials. Direct shear tests were conducted on samples, the results of which showed that as a result of incorporating these wastes into the soil, friction angle and shear strength of sand increased. Consoli et al. [20] conducted an experimental study on the uncemented and artificially cemented soils reinforced with polyethylene fibers derived from plastic wastes. Their results demonstrated that plastic wastes could improve the stress-strain response of both uncemented and cemented sands. Kim et al. [21] investigated the behavior of the reinforced and unreinforced lightweight soils. The results of both unconfined compression and one-dimensional compression tests showed that the strength of reinforced lightweight soil generally increased after adding waste fishing net $(0 \%, 0.25 \%$, $0.5 \%, 0.75 \%$, and $1 \%$ of the dry soil weight); however, the degree of increase in the compressive strength was not directly proportional to the percentage of waste fishing net. The results of the tests indicated that maximum increase in the compressive strength was obtained for soil mixed with $0.25 \%$ waste fishing net. Babu and Chouksey [22] conducted experiments on sand samples reinforced with waste PET pieces $(0.5 \%$, $0.75 \%$, and $1 \%$ of dry soil weight) obtained from waste water bottles. They observed that inclusion of these plastics in the soil improved the shear strength, tensile strength, and internal friction angle of the soil. Muntohar et al. [23] carried out an experimental study on silty soil stabilized by lime and rice husk ash and reinforced with waste plastic fibers. The results pointed to the efficacy of this method in improving the engineering properties of the silty soil in terms of compressive strength, tensile strength, and shear strength, which enhanced the stability of the soil. Further, the optimum amount of fiber in the soil/lime/rice husk ash/fiber mixtures ranged from $0.4 \%$ to $0.8 \%$ of the weight of dry soil. Abbaspour et al. [7] performed a series of static and cyclic laboratory tests to manage and prevent the burial of a part of hazardous wastes produced during the recycling process of worn tires. According to their results, fiber inclusion could enhance all geotechnical properties of the soil in the static state. They concluded that under a dynamic state, fibers could increase energy absorption and dissipation properties of the soil as well as the resilient modulus and damping ratio with an optimum fiber content of $1-2 \%$.

Therefore, based on the previous researches, using short fibers over planar reinforcement enjoys several main advantages summarized below:

1. Improving the physical properties of soil;

2. Providing greater uniformity;
3. Offering considerable flexibility;

4. Ensuring high levels of stiffness to weight ratio;

5. Increasing the toughness, i.e., more energy absorption ability.

This property is suitable for subgrades of airport pavements, blast resistant structures, etc.

This paper presents an experimental study of the application of two types of fiber-shaped plastic wastes (PET and PP) for sand reinforcement and evaluated their effects on shear strength, ductility, and stiffness of the sand. In addition, the effects of plastic waste fiber content, confining pressure, and length of PET fibers on the sand behavior were examined.

\section{Materials}

\subsection{Sand}

The sand used in this research was collected from shores of Caspian Sea (Babolsar, Iran). The grain size distribution curve of the soil, obtained based on ASTM D-422 [24], is shown in Figure 1. The sand found in Babolsar is uniform and clean with subrounded to sub-granular particles and classified as SP according to the unified soil classification system, ASTM D2487 [25]. The mean particle diameter $\left(D_{50}\right)$ of the sand was $0.2 \mathrm{~mm}$. The specific gravity of sand particles was calculated as 2.75 based on ASTM D-854 [26]. Minimum and maximum dry unit weights of the sand were obtained using ASTM D-4254 [27] and ASTM D4253 [28] equal to 14.8 and $17.4 \mathrm{kN} / \mathrm{m}^{3}$, respectively.

\subsection{Reinforcing materials}

The reinforcing materials used in this study included two kinds of plastic wastes: Poly-Ethylene Terephthalate (PET) and Poly-Propylene (PP). The PET waste was recycled from plastic water bottles. These plastic water bottles were accumulated and then, melted to transform into fiber-shaped material. The fibers were

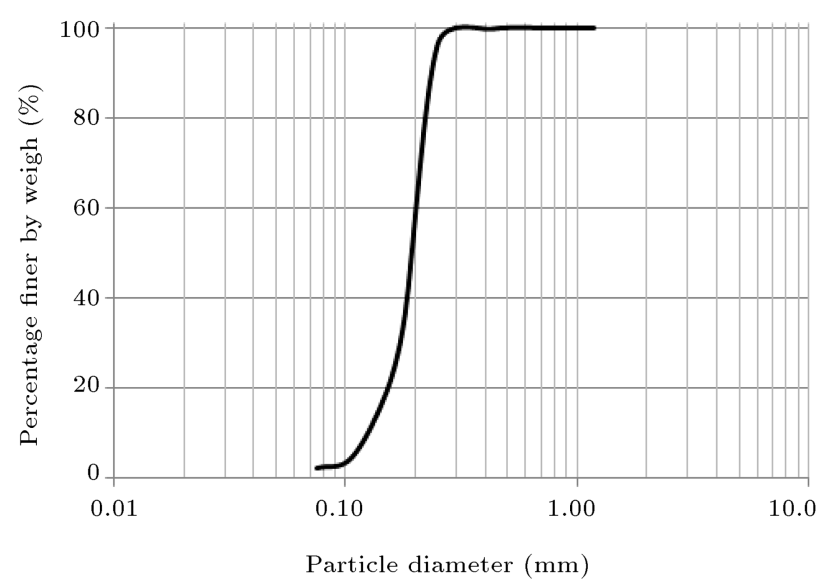

Figure 1. Grain size distribution curve for the sand in Babolsar, Iran. 


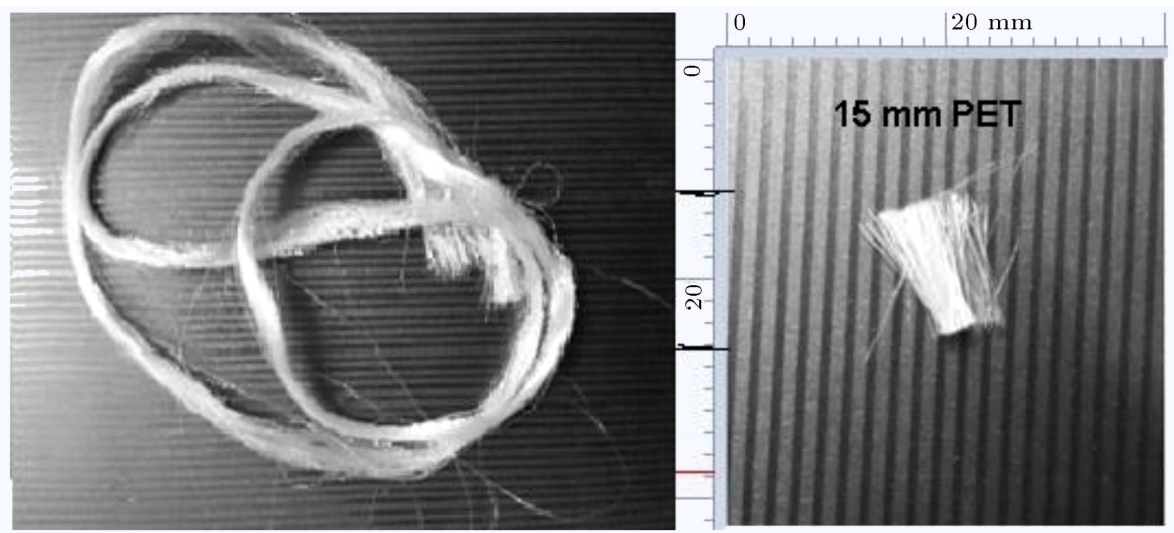

Figure 2. Recycled PET fibers.

Table 1. Characteristics of the fibers used.

\begin{tabular}{ccccccc}
\hline $\begin{array}{c}\text { Fiber } \\
\text { type }\end{array}$ & $\begin{array}{c}\text { Length } \\
(\mathbf{m m})\end{array}$ & $\begin{array}{c}\text { Width } \\
\mathbf{( m m})\end{array}$ & $\begin{array}{c}\text { Diameter } \\
\mathbf{( m m})\end{array}$ & $\begin{array}{c}\text { Specific gravity } \\
\left(\mathbf{g} / \mathbf{c m}^{3}\right)\end{array}$ & $\begin{array}{c}\text { Elastic modulus } \\
(\mathbf{G P a})\end{array}$ & $\begin{array}{c}\text { UTS }^{*} \\
(\mathbf{M P a})\end{array}$ \\
\hline $\mathrm{PET}^{\times}$ & $5,10,15$ & - & $0.4-0.8$ & 0.92 & 0.65 & 200 \\
$\mathrm{PP}^{\bullet}$ & 15 & $2-2.5$ & - & 0.92 & 3.2 & 300 \\
\hline
\end{tabular}

*: Ultimate tensile strength; $\times$ : Polyethylene terephthalate; •: Polypropylene.

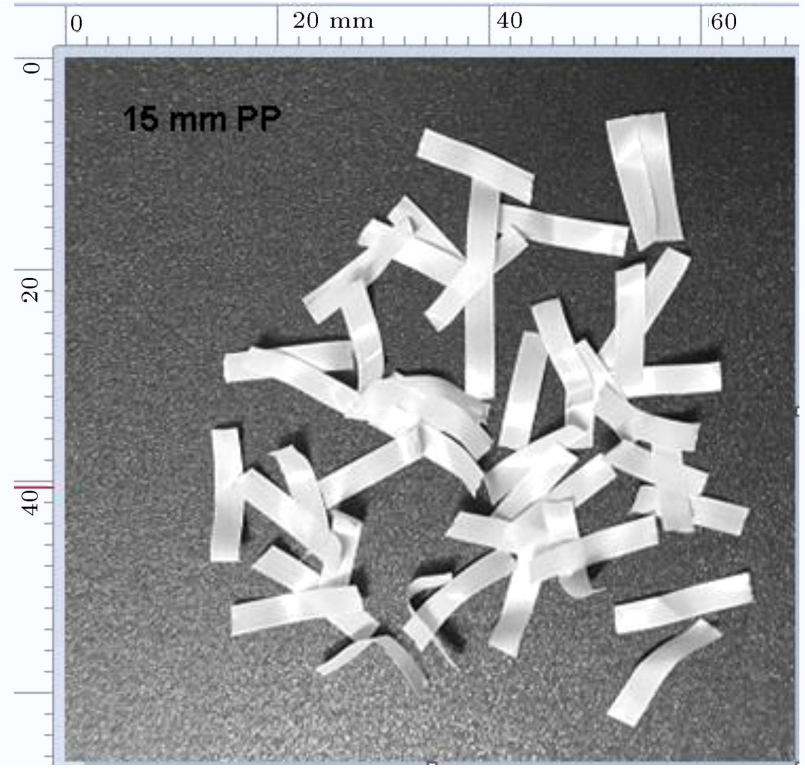

Figure 3. Waste PP fibers.

cut into 5-, 10-, and 15-mm pieces to be used as the reinforcing elements in sand (Figure 2). The waste PP fibers were taken from a factory that produced polypropylene bags and then, they were cut into $15 \mathrm{~mm}$ long pieces (Figure 3). The characteristics of the used fibers are given in Table 1 .

\section{Sample preparation and testing procedure}

To prepare the samples mixed with PET fibers, an appropriate amount of the sand and plastic waste should be weighed. To ensure uniform distribution of PET fibers in the mixture, the selected dry soil was first mixed with $5 \%$ water content and then, the determined weight of the plastic waste (by dry weight of the soil) was mixed with soil until a uniform mixture was obtained (It was suggested to add a specific amount of water to the sand to achieve a better mixture of sand and fiber until it does not cause them to float.) [29]. To determine the required amount of water in this study for preparing the samples, different water contents including 5, 10, and 15\% were considered and the homogeneity of samples was evaluated. Based on the results, $5 \%$ water content was selected as the optimum moisture content to prepare the uniform sand-fiber mixtures. Since the tests were carried out on dry specimens, the mixtures were put into an oven at $65^{\circ} \mathrm{C}$ (the maximum suitable temperature used for preventing the PET from deformation fibers) for 48 hours prior to the tests to get dried.

To prepare the mixtures with PP fibers, the determined amount of sand was mixed with $\mathrm{PP}$ fibers in a dry condition.

Following a mixture of sand and plastic wastes, the specimens were statically compacted in four layers in a cylindrical mold with a diameter and a height of $38 \mathrm{~mm}$ and $76 \mathrm{~mm}$ (similar to the model used by Yadav and Tiwari [18] for the fiber with the maximum length of $15 \mathrm{~mm}$ ), respectively, and a relative density of $70 \%$ based on the procedure proposed by Baldi et al. [30]. Both types of plastic wastes were mixed with sand at different percentages $(0,0.25,0.5,0.75$, and $1 \%$ by dry soil weight). 
The prepared samples were tested in a dry condition in a conventional triaxial apparatus. A number of studies have been conducted on dry samples of granular soils in the literature [31-33]. In this study, variations in the volume of the specimens were recorded and measured in order to monitor this property during the shear and to apply it in area correction. A twin-burette volume change was taken into account to measure changes in the volume of specimens on the cell pressure line. A total of 51 triaxial compression tests were performed on the unreinforced and reinforced specimens at a strain rate of $0.35 \%$ per minute. The tests were performed on the samples with three values of confining pressures $(50,100$, and $200 \mathrm{kPa})$. Deviator load was applied till the specimens fail or attain the axial strain of $15 \%$. Corrections including membrane force [34], membrane penetration [35], and cross-sectional area were also taken into account. The investigated variables are depicted in Table 2.

Table 2. Variable factors in the testing program.

\begin{tabular}{ll}
\hline Variable & \multicolumn{1}{c}{ Range } \\
\hline Confining pressure & 50,100, and $200 \mathrm{kPa}$ \\
Plastic waste content & $0,0.25,0.5,0.75$, and $1 \%$ \\
Waste PET length & 5,10, and $15 \mathrm{~mm}$ \\
Waste PP length & $15 \mathrm{~mm}$ \\
\hline
\end{tabular}

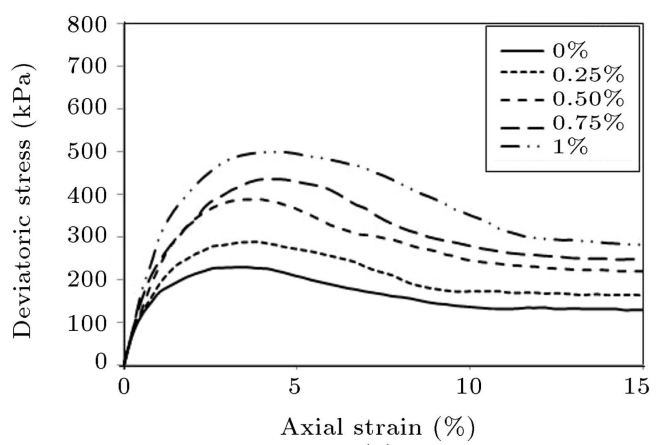

(a)

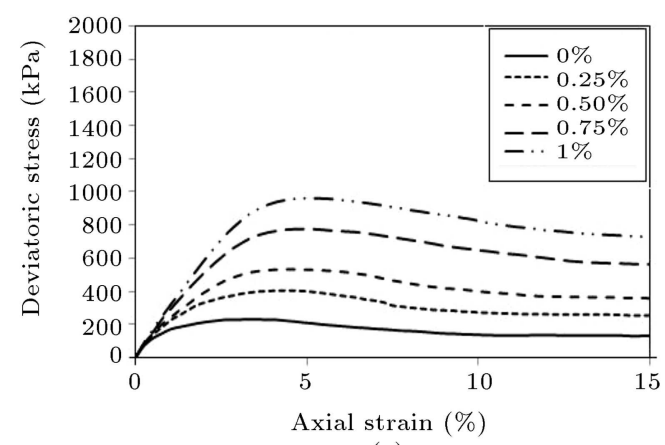

(c)

\section{Results and discussion}

In this section, the results of the performed triaxial compression tests on the specimens of unreinforced and reinforced sands with two types of plastic wastes are presented in terms of peak strength, ductility, failure strain, volumetric strain, and secant modulus of deformation.

\subsection{Effect on peak strength}

According to Figure 4, the peak strength increased upon reinforcement of the sand. This increment became more considerable with an increase in the percentage and length of plastic wastes. For instance, the peak strength of the unreinforced sand under a confining pressure of $50 \mathrm{kPa}$ increased from 230.5 to $288.8 \mathrm{kPa}$ due to the reinforcement by $0.25 \%$ PET with $5 \mathrm{~mm}$ length. This value increased to $961.3 \mathrm{kPa}$ (more than 4 times of the unreinforced one) for a sample reinforced by $1 \%$ PET with $15 \mathrm{~mm}$ length. Furthermore, for PP waste fiber-reinforced sand at $1 \%$ usage, the peak strength reached $1614 \mathrm{kPa}$ (about 7 times of the unreinforced one) for the same confining pressure. A similar trend was observed in previous studies $[4,12,13,20]$. Since the plastic waste reinforced sand was subjected to deformation, the friction appearing between soil and plastic wastes could develop the tensile stress in the plastic wastes, increase the sample confinement, and consequently increase the

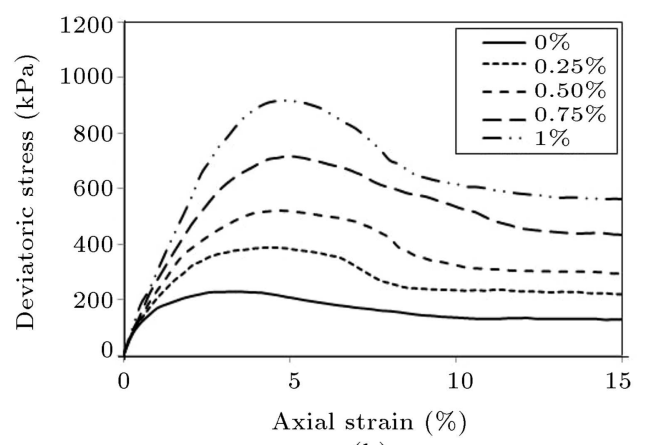

(b)

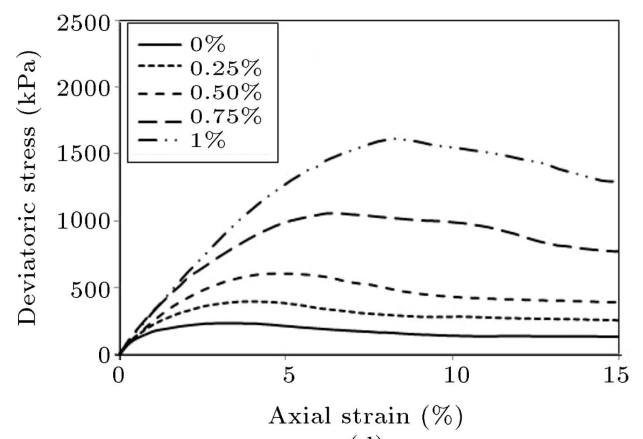

(d)

Figure 4. Stress-strain curves at a confining pressure of $50 \mathrm{kPa}$ : (a) For different PET fiber contents with a length of 5 $\mathrm{mm}$, (b) different PET fiber contents with a length of $10 \mathrm{~mm}$, (c) different PET fiber contents with a length of $15 \mathrm{~mm}$, and (d) different PP fiber contents with a length of $15 \mathrm{~mm}$. 


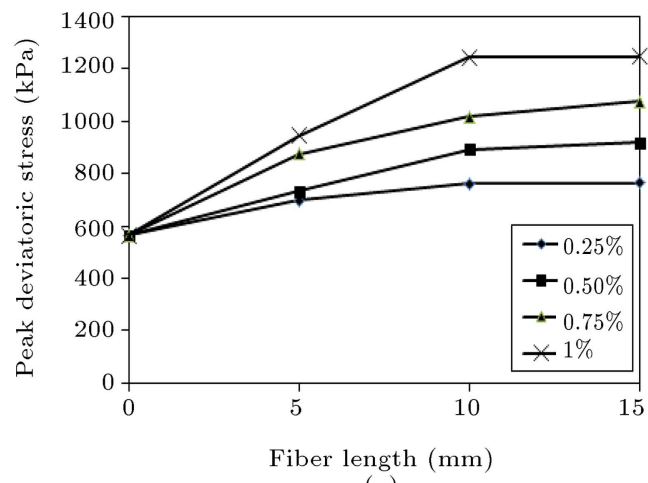

(a)

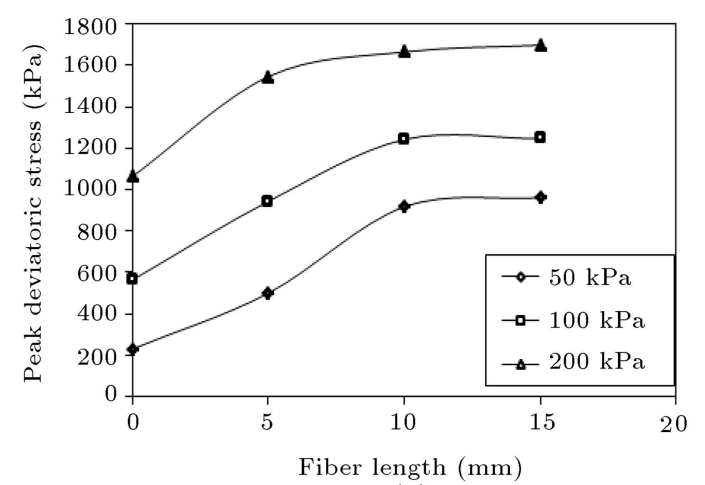

(b)

Figure 5. Effect of PET fiber length on the peak deviatoric stress: (a) For the confining pressure of $100 \mathrm{kPa}$ and different PET contents, and (b) for $1 \%$ PET and different confining pressures.

shear strength of the samples. As observed in Figure 5, for all PET contents and confining pressures, the peak shear stress of the sand was enhanced upon an increase in the length of waste PET fibers from $5 \mathrm{~mm}$ to 10 $\mathrm{mm}$; however, at higher values, the improvement of shear stress was negligible probably due to the fact that longer fibers had longer embedment length, thus enduring greater tension during shear. In fact, the amount of increase in the peak shear stress for the sand reinforced with PET fibers $15 \mathrm{~mm}$ in length was almost the same as that for the sand reinforced with fibers $10 \mathrm{~mm}$ in length with a negligible difference. Previous researches have also witnessed a similar trend between the shear strength improvement of fiber-reinforced soil and length of the fiber [4]. This phenomenon can be justified for the following reasons:

- There is a decrease in the number of fibers existing in the failure zone. In other words, in case the percentage of the fiber was kept constant, the number of fibers would decrease with an increase in the fiber length;

- As the fiber length increased, it became more difficult to make a uniform mixture with the sand because the long fibers piled up together would lead to slippage. Hence, less improvement was observed in case the percentage of the fiber would be constant in soil and the length of waste plastic fibers increased.

Nevertheless, the stress ratio (ratio of peak deviatoric stress of the reinforced specimen to the corresponding value of the unreinforced one) decreased with an increase in the confining pressure, as shown in Figure 6. For instance, in the sample reinforced by $1 \%$ PET with a length of $15 \mathrm{~mm}$, the stress ratio at a confining pressure of $50 \mathrm{kPa}$ is 3.98 , while it is about 1.57 at a confining pressure of $200 \mathrm{kPa}$. A similar trend was observed in previous studies $[4,32,36,37]$. Improvement of shear strength in dilating soils, with the inclusion

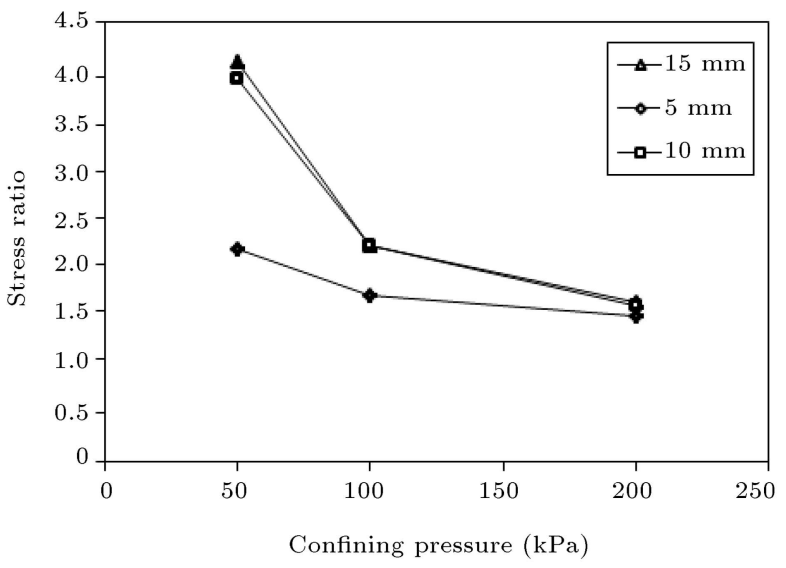

Figure 6. Stress ratio versus confining pressure for the sand reinforced by $1 \%$ PET with different lengths.

of fibers, is related to the level of interaction between fibers and soil particles as well as the amount of dilation during the shear stage that mobilized the tensile strength of fibers. Dilatancy is the result of shear zone expansion during the mobilization of the reinforcing elements. An increase in the confining pressure limits the rearrangement of the soil structure that finally results in lower dilation, thus restricting the amount of fiber stretches during the shear $[4,32,36]$. Hence, the efficiency of the fiber reinforcement in increasing the shear strength of the dilating soil is obviously susceptible to any increase in the confining pressure. Evidently, the stress ratio of fiber-reinforced sand was reduced from 4 at a confining pressure of $50 \mathrm{kPa}$ to a value 1.5 times that of the unreinforced sand at a confining pressure of $200 \mathrm{kPa}$; therefore, it can be concluded that the efficiency of fibers in increasing the shear strength of medium dense sand would be reduced at high confining pressures regardless of the fiber content. To reach the maximum efficiency, using these fibers as the reinforcement for soils with low-to-medium overburden stress range such as base layer in road construction is recommended. 
Table 3. Strength properties of the reinforced and unreinforced sands.

\begin{tabular}{|c|c|c|c|}
\hline Material & $\begin{array}{c}\text { Confining pressure } \\
(\mathbf{k P a})\end{array}$ & $\begin{array}{l}\text { Peak stress at failure } \\
\qquad(\mathbf{k P a})\end{array}$ & $\begin{array}{c}\text { Steady state stress } \\
(\mathrm{kPa})\end{array}$ \\
\hline \multirow{15}{*}{ Sand } & 50 & 230.5 & 130.1 \\
\hline & 100 & 563 & 343 \\
\hline & 200 & 1063.2 & 747.6 \\
\hline & 50 & 500.2 & 282.2 \\
\hline & 100 & 943.5 & 602.7 \\
\hline & 200 & 1546.1 & 1132.2 \\
\hline & 50 & 917.3 & 563.7 \\
\hline & 100 & 1242.2 & 880.3 \\
\hline & 200 & 1665.4 & 1437.3 \\
\hline & 50 & 961.3 & 730 \\
\hline & 100 & 1246.6 & 939.7 \\
\hline & 200 & 1698 & 1472.3 \\
\hline & 50 & 1614 & 1289 \\
\hline & 100 & 2198.6 & 1889.8 \\
\hline & 200 & 2691.9 & 2399.7 \\
\hline \multirow{3}{*}{$\begin{array}{c}\text { Sand }+1 \% \text { waste PET } \\
(5 \mathrm{~mm})\end{array}$} & 50 & 500.2 & 282.2 \\
\hline & 100 & 943.5 & 602.7 \\
\hline & 200 & 1546.1 & 1132.2 \\
\hline \multirow{3}{*}{$\begin{array}{c}\text { Sand }+1 \% \text { waste PET } \\
(10 \mathrm{~mm})\end{array}$} & 50 & 917.3 & 563.7 \\
\hline & 100 & 1242.2 & 880.3 \\
\hline & 200 & 1665.4 & 1437.3 \\
\hline \multirow{3}{*}{$\begin{array}{c}\text { Sand }+1 \% \text { waste PET } \\
(15 \mathrm{~mm})\end{array}$} & 50 & 961.3 & 730 \\
\hline & 100 & 1246.6 & 939.7 \\
\hline & 200 & 1698 & 1472.3 \\
\hline \multirow{3}{*}{ Sand $+1 \%$ waste PP } & 50 & 1614 & 1289 \\
\hline & 100 & 2198.6 & 1889.8 \\
\hline & 200 & 2691.9 & 2399.7 \\
\hline
\end{tabular}

The results obtained from the conducted tests indicated that for all different waste contents and confining pressures, the sand reinforced with PP plastic wastes had a higher peak deviatoric stress than that reinforced with waste PET fibers. For instance, the results of the tests conducted at a confining pressure of $50 \mathrm{kPa}$ indicated that the peak shear stress in the sand reinforced with the PET fiber $15 \mathrm{~mm}$ in length (Figure 4(c)) was 4.17 times greater than that in the unreinforced sand; in addition, the stress in the sand reinforced with waste PP fibers (Figure $4(\mathrm{~d})$ ) was 7 times greater than that in the unreinforced one. These values were obtained for specimens with $1 \%$ plastic waste, considering the tensile strength of wastes. Since the tensile strength of PP fibers was higher than that of the PET fibers, the PP fibers were crushed during the shearing (Figure 7); however, the PET fibers were torn in the failure zone.

\subsection{Effect on ductility}

According to Figure 4 and Table 3, the post-peak loss of shear stress for reinforced specimens was reduced. In fact, the steady state stress of reinforced samples increased upon an increase in the content and length of plastic wastes. This can be justified by the fact that when the samples are loaded, the fibers act like a bridge and prevent the occurrence of early and large deformations in the soil. As a result, the soil shows significant strength against larger strains and less strength decline. Therefore, the brittleness index, indicative of the fragility and ductility of the reinforced soil, was calculated based on Bishop's [38] definition (Eq. (1)), as depicted in Table 4, and it decreased after adding waste fibers to the soil.

$$
I_{B}=\frac{q_{p}-q_{s}}{q_{p}}
$$


Table 4. Brittleness index for the sand reinforced by plastic waste at a confining pressure of $100 \mathrm{kPa}$.

\begin{tabular}{lccccc}
\hline \multirow{2}{*}{ Material } & \multicolumn{5}{c}{ Plastic waste content } \\
\cline { 2 - 6 } & $0 \%$ & $0.25 \%$ & $0.5 \%$ & $0.75 \%$ & $1 \%$ \\
\hline Sand + waste PET (5 mm) & 0.64 & 0.61 & 0.61 & 0.59 & 0.57 \\
Sand + waste PET (10 mm) & 0.64 & 0.53 & 0.44 & 0.43 & 0.41 \\
Sand + waste PET (15 mm) & 0.64 & 0.51 & 0.43 & 0.38 & 0.32 \\
Sand + waste PP & 0.64 & 0.56 & 0.31 & 0.25 & 0.16 \\
\hline
\end{tabular}

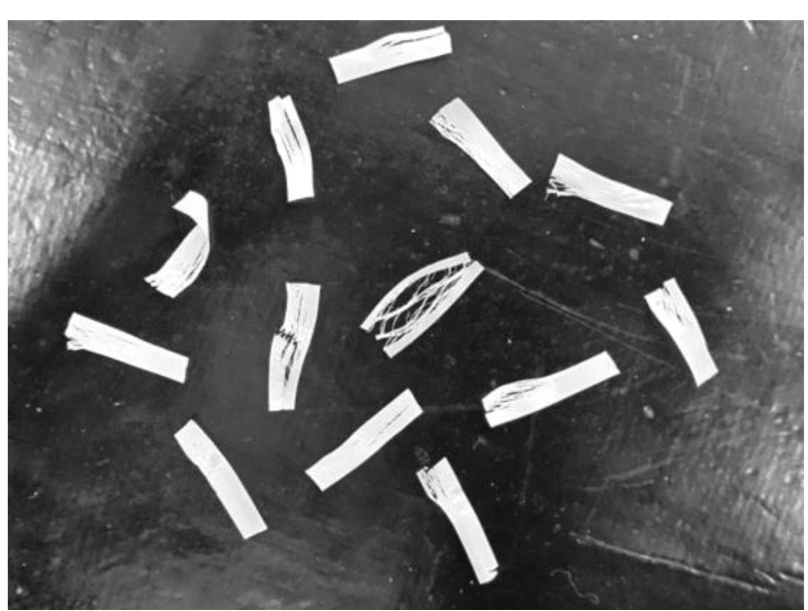

Figure 7. Waste PP fibers in the failure zone.

where $I_{B}$ is brittleness index, $q_{p}$ peak shear stress, and $q_{s}$ the steady state shear stress.

According to Table 4, the brittleness index of the reinforced specimens decreased with an increase in the length and percentage of the waste fiber. However, the extent of this reduction was quite small for the sand reinforced by PET fibers with a length of $5 \mathrm{~mm}$ (approximately $11 \%$ for $1 \%$ usage). However, the greatest reduction in the brittleness index was observed for the waste PP-reinforced sand (about $75 \%$ for $1 \%$ usage). In other words, the sand reinforced by the waste PP fibers showed a more ductile behavior than that reinforced by the waste PET fibers. The reason behind this behavior

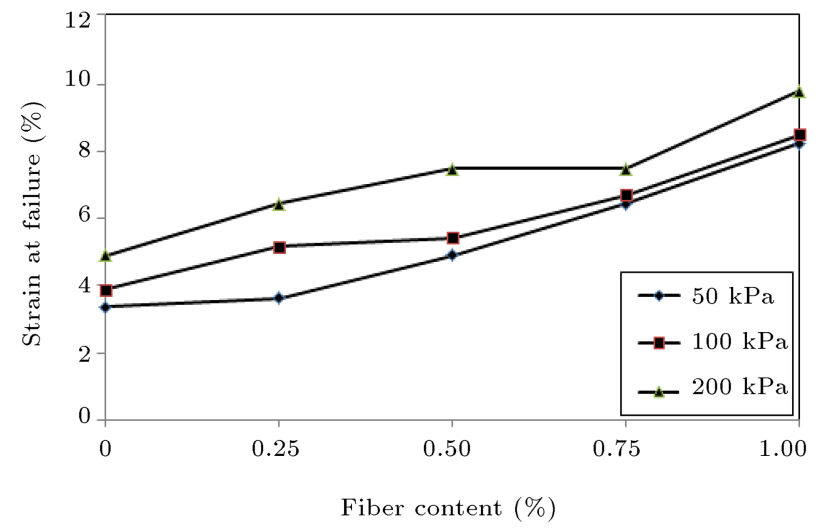

Figure 9. Effect of PP fiber content on strain at failure at different confining pressures.

lies in the tensile strength of wastes, as elaborated earlier. Generally, it can be argued that the ductility of the sand in Babolsar was improved after reinforcement with plastic wastes. Increasing soil ductility would enhance the seismic stability of geotechnical projects such as airport runways and rail embankments [39].

\subsection{Effect on failure strain}

As demonstrated in Figures 8 and 9, the sand reinforced by plastic waste had a greater axial strain upon failure than the unreinforced sand, and the strain upon failure increased with an increase in the content and length of the fiber-shaped waste. For instance, for the sample reinforced by $1 \% \mathrm{PP}$ under the confining
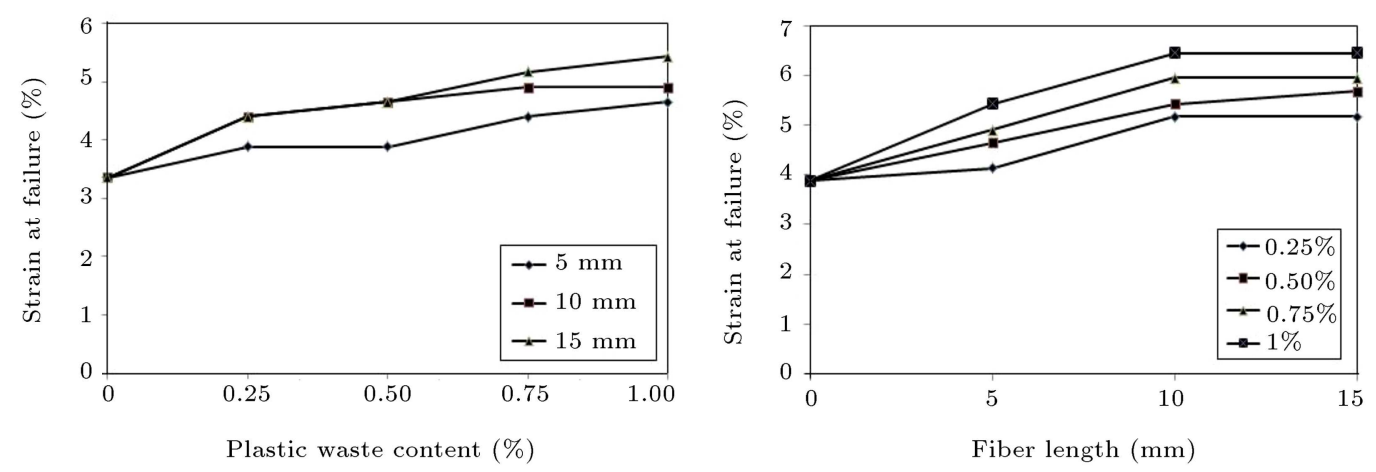

Figure 8. Effect of PET: (a) Fiber content on strain at failure at a confining pressure of $50 \mathrm{kPa}$ and (b) fiber length on strain at failure at a confining pressure of $100 \mathrm{kPa}$. 
pressure of $50 \mathrm{kPa}$, the axial strain upon failure increased up to 1.5 times that of the unreinforced one (from 3.36 to $8.53 \%$ ). In fact, at all confining pressures, the axial strain at failure increased with an increase in the plastic waste percentage. As stated earlier, such an increase can be attributed to the friction emerging between the soil and plastic waste fibers (when the load applied to the specimen), which would lead to development of tensile stress in the plastic wastes. In addition, this tensile stress can cause confining pressure in the sample, which results in an increase in the axial strain at failure in the reinforced samples [22]. Due to the greater tensile strength of PP waste fiber (as mentioned earlier), the amount of increase in the axial strain at failure for the PP-fiber reinforced sand is higher than that for the PET-fiber reinforced sand.

\subsection{Effect on volumetric strain}

The changes in the volumetric strain against axial strain for unreinforced and reinforced sands with plastic waste (PET) are presented in Figure 10. A closer look at this figure shows the following:

1. As expected in the primary section, both of the unreinforced and reinforced samples exhibited small contraction in their volumes. With advance in shear stress, the trend was reverted and the samples showed an increase in their volumes. However, an increase in the confining pressure restricted their volumetric dilation;

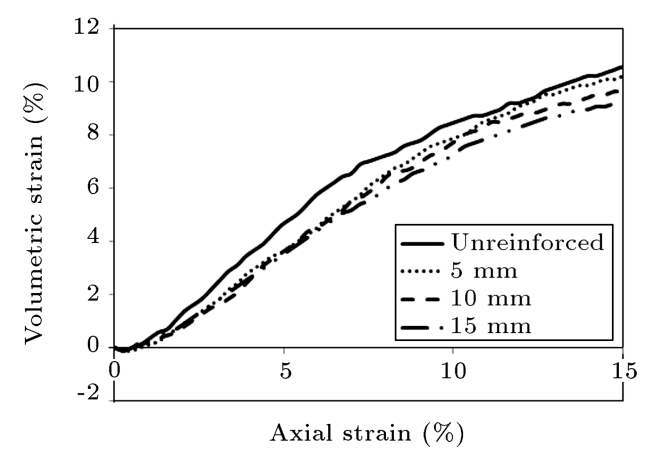

(a)

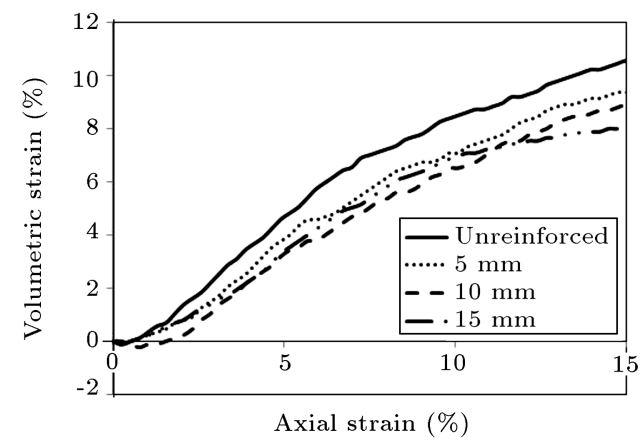

(c)
2. The dilation of specimens decreased by introducing the plastic wastes (PET). Numerous researchers $[40,41]$ have reported that the dilation occurred principally at the center of samples. Dilation and lateral deformation at the top and bottom of the specimen were restrained by both cap and base. Moreover, many researchers believe that plastic fibers can reduce lateral deformation. As already mentioned, inclusion of fiber to the sand due to the friction emerging between the soil and plastic waste could intensify the confinement of the sample, thus decreasing the lateral deformation. Therefore, it is clear that plastic waste fibers can efficiently reduce the dilation of the specimens. A similar behavior was reported in previous researches $[37,40,41]$. This phenomenon may be attributed to the decrease in the maximum dry unit weight of the sand resulting from the inclusion of fiber to the specimen as well as the small size of fiber holes compared to the $D_{50}$ of the sand. In case of an increase in the content and length of PET, this finding becomes more obvious.

\subsection{Effect on secant modulus of deformation}

The secant deformation modulus $\left(E_{50}\right)$, shown in Figure 11, increased with an increase in the waste content for two types of wastes (PET and PP) and all lengths. For the sample reinforced by $1 \%$ PET with a length of $5 \mathrm{~mm}$, the value of this increment was the

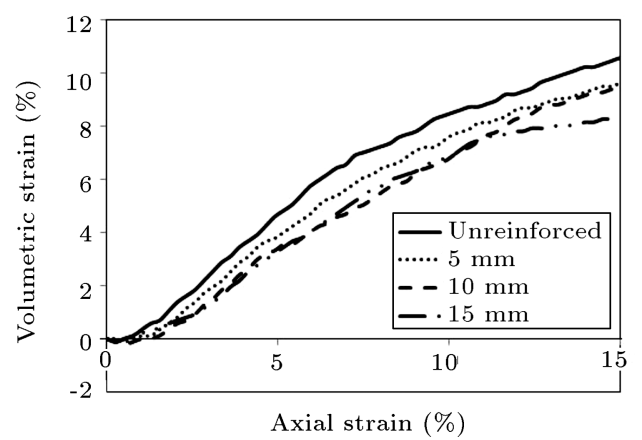

(b)

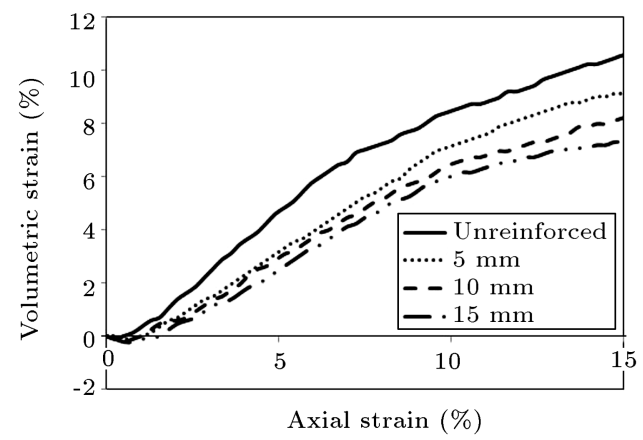

(d)

Figure 10. Volumetric change curves for PET fibers with different lengths and at a confining pressure of $50 \mathrm{kPa}$ : (a) Fiber content of $0.25 \%$, (b) fiber content of $0.5 \%$, (c) fiber content of $0.75 \%$, and (d) fiber content of $1 \%$. 


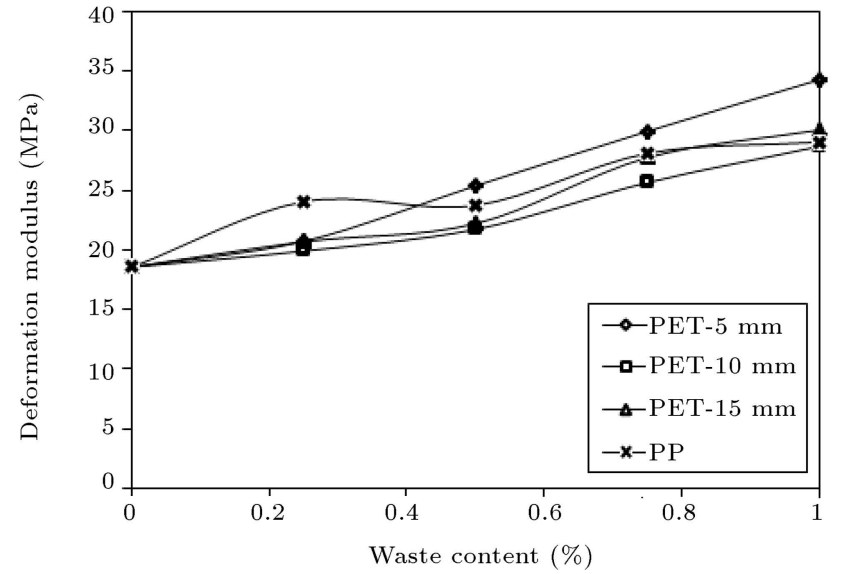

Figure 11. Deformation modulus of the reinforced sand by different contents of plastic wastes at a confining pressure of $50 \mathrm{kPa}$.

highest. To be specific, $E_{50}$ increased from $18.6 \mathrm{MPa}$ for the unreinforced sample to $34.2 \mathrm{MPa}$ (about $84 \%$ increment) for the mentioned sample at a confining pressure of $50 \mathrm{kPa}$. Furthermore, upon increasing the length of the plastic waste, the peak strength and axial strain at failure would increase. Therefore, for the reinforced sample with shorter fiber lengths, the increase in the axial strain was more limited than that in the peak strength. As a result, the value of $E_{50}$ increased further in this case. Moreover, this figure shows that the amount of increase in $E_{50}$ decreased by increasing PET length; however, for reinforced samples with PET lengths of 10 and $15 \mathrm{~mm}$, this amount is almost the same (similar to the results obtained for the peak strength of these two samples). Moreover, since $\mathrm{PP}$ is characterized by a greater strength than PET, the sample reinforced by $\mathrm{PP}$ with a length of $15 \mathrm{~mm}$ had a higher $E_{50}$ value than that reinforced by PET with a length of $15 \mathrm{~mm}$.

The results of this study showed that the application of PET and PP waste fibers in soil reinforcement could significantly improve the soil behavior. The final improvement in reinforcement with $\mathrm{PP}$ waste fiber remains more significant than $\mathrm{PET}$ one, although both of them could significantly improve the soil properties. Depending on the expected conditions and type of available plastic wastes in the area, each of the waste fiber types can be used so that both the environmental effects of the existence of waste can be reduced (as stated by Hejazi et al. [3], plastic wastes are mainly used in geotechnical engineering for environmental purposes) and the behavior of the soil is improved according to the results of this research.

\section{Conclusions}

The present study shares the idea of reusing plastic wastes in geotechnical engineering applications. A series of triaxial compression tests were conducted on the reinforced sand using these materials. The content of these fiber-shaped plastic wastes varied from 0 to $1 \%$. The effects of four factors, i.e., the type, length, content, and confining pressure of the plastic wastes, on the behavior of plastic waste reinforced sand were also investigated. The experimental results indicated that:

1. Shear strength of sand increased following the inclusion of both kinds of plastic wastes. Given that the plastic-waste-reinforced sand was exposed to deformation, the friction appearing between the soil and plastic wastes would cause the development of tensile stress in the plastic wastes, increase in the confinement of the sample, and consequently increase in the shear strength of the samples;

2. The amount of increase in the peak stress was intensified after increasing the PET fiber with the lengths of 5 to $10 \mathrm{~mm}$, mainly because longer fibers had a longer embedment length; besides, at higher values, the improvement of the peak stress was negligible;

3. The peak shear strength of the PP fiber-reinforced sand (for $1 \%$ fiber addition, about 7 times the unreinforced sand) was greater than the PET fiberreinforced sand (for $1 \%$ fiber addition and $15 \mathrm{~mm}$ length, about 4.17 times the unreinforced sand) due to the greater tensile strength of this fiber;

4. The stress ratio (ratio of the peak deviatoric stress of the reinforced specimen to the corresponding value of the unreinforced one) decreased from 3.98 to about 1.57 (for the sample reinforced by $1 \%$ PET with the length of $15 \mathrm{~mm}$ ) with an increase in the confining pressure from 50 to $200 \mathrm{kPa}$. In addition, increasing the confining pressure could limit rearrangement of the soil structure resulting in less dilation, thus restricting the amount of fiber stretch during the shear;

5. The inclusion of fiber-shaped plastic wastes to the sand made its behavior more ductile and reduced its brittleness index (up to $75 \%$ ). In the reinforced sample, the fibers acted like a bridge and prevented the occurrence of early and large deformations in the soil. As a result, the soil showed significant strength against larger strains and lower strength decline;

6. Due to the fiber inclusion to the sand, the strain of the fiber reinforced sand at failure increased up to 1.5 times that of the unreinforced one (from 3.36 to $8.53 \%$ for $1 \% \mathrm{PP}$ usage at a confining pressure of $50 \mathrm{kPa}$ ) because of the friction appearing between the soil and plastic waste fibers;

7. The dilation of the plastic waste reinforced sand decreased by about $30 \%$ with an increase in the 
content and length of the plastic waste. This phenomenon could be attributed to the decrease in the maximum dry unit weight of the sand resulting from the inclusion of fiber to the specimen;

8. The secant deformation modulus $\left(E_{50}\right)$ increased with an increase in the fiber (waste) content. The maximum increment was observed for the sample reinforced by $1 \%$ PET with a length of $5 \mathrm{~mm}$ (about $84 \%)$.

\section{Acknowledgement}

The authors acknowledge the funding support obtained from Babol Noshirvani University of Technology through Grant program No. BNUT/370342/98.

\section{References}

1. Tang, C., Shi, B., Gao, W., Chen, F., and Cai, Y. "Strength and mechanical behavior of short polypropylene fiber reinforced and cement stabilized clayey soil", Geotextiles and Geomembranes, 25(3), pp. 194-202 (2007).

2. Bendjillali, K. and Chemrouk, M. "Efficiency of plastic fibres waste on the physico-mechanical properties of mortars in hot-dry conditions", International Journal of Natural Sciences Research, 4(4), pp. 75-82 (2016).

3. Hejazi, S.M., Sheikhzadeh, M., Abtahi, S.M., and Zadhoush, A. "A simple review of soil reinforcement by using natural and synthetic fibers", Construction and Building Materials, 30, pp. 100-116 (2012).

4. Mirzababaei, M., Arulrajah, A., Haque, A., Nimbalkar, S., and Mohajerani, A. "Effect of fiber reinforcement on shear strength and void ratio of soft clay", Geosynthetics International, 25(4), pp. 471-480 (2018).

5. Choudhary, A.K., Jha, J.N., and Gill, K.S. "Utilization of plastic wastes for improving the sub-grades in flexible pavements", In Paving Materials and Pavement Analysis, pp. 320-326 (2010).

6. Eweed, K.M., Ebrahim, Y.K., and Ali, R.S. "Effecting the addition of the plastic waste and rubber on the constructions materials properties", In IOP Conference Series: Materials Science and Engineering, 454(1), 012151 (2018).

7. Abbaspour, M., Narani, S.S., Aflaki, E., and Nejad, F.M. "Behavior of a subgrade soil reinforced by waste tire textile fibers under static and cyclic loading", Journal of Materials in Civil Engineering, 32(8), 04020208 (2020).

8. Abbaspour, M., Narani, S.S., Aflaki, E., Moghadas Nejad, F., and Mir Mohammad Hosseini, S.M. "Strength and swelling properties of a Waste Tire Textile Fiber (WTTF)-reinforced expansive soil", Geosynthetics International, pp. 1-14 (2020).
9. Narani, S.S., Abbaspour, M., Hosseini, S.M.M., Aflaki, E., and Nejad, F.M. "Sustainable reuse of Waste Tire Textile Fibers (WTTFs) as reinforcement materials for expansive soils: With a special focus on landfill liners/covers", Journal of Cleaner Production, 247, $119151(2020)$

10. Foose, G.J., Benson, C.H., and Bosscher, P.J. "Sand reinforced with shredded waste tires", Journal of Geotechnical Engineering (ASCE), 122(9), pp. 760767 (1996).

11. Zornberg, J.G., Cabral, A.R., and Viratjandr, C. "Behaviour of tire shred-sand mixtures", Canadian Geotechnical Journal, 41(2), pp. 227-241 (2004).

12. Ghazavi, M. "Shear strength characteristics of sandmixed with granular rubber", Geotechnical and Geological Engineering, 22(3), pp. 401-416 (2004).

13. Mashiri, M.S., Vinod, J.S., Sheikh, M.N., and Tsang, H.H. "Shear strength and dilatancy behaviour of sandtyre chip mixtures", Soils and Foundations, 55(3), pp. 517-528 (2015).

14. Indraratna, B., Sun, Q., and Grant, J. "Behaviour of subballast reinforced with used tyre and potential application in rail tracks", Transportation Geotechnics, 12, pp. 26-36 (2017).

15. Narani, S.S., Abbaspour, M., Hosseini, S.M.M., and Nejad, F.M. "Long-term dynamic behavior of a sandy subgrade reinforced by Waste Tire Textile Fibers (WTTFs)", Transportation Geotechnics, 24, 100375 (2020).

16. Soltani, A., Deng, A., Taheri, A., Mirzababaei, M., and Nikraz, H. "Interfacial shear strength of rubberreinforced clays: A dimensional analysis perspective", Geosynthetics International, 26(2), pp. 164-183 (2019).

17. Abbaspour, M., Aflaki, E., and Nejad, F.M. "Reuse of waste tire textile fibers as soil reinforcement", Journal of Cleaner Production, 207, pp. 1059-1071 (2019).

18. Yadav, J.S. and Tiwari, S.K. "Effect of waste rubber fibres on the geotechnical properties of clay stabilized with cement", Applied Clay Science, 149, pp. 97-110 (2017).

19. Benson, C.H. and Khire, M.V. "Reinforcing sand with strips of reclaimed high-density polyethylene", Journal of Geotechnical Engineering (ASCE), 120(5), pp. 838855 (1994).

20. Consoli, N.C., Montardo, J.P., Prietto, P.D.M., and Pasa, G.S. "Engineering behavior of a sand reinforced with plastic waste", Journal of Geotechnical and Geoenvironmental Engineering (ASCE), 128(6), pp. 462-472 (2002).

21. Kim, Y.T., Kim, H.J., and Lee, G.H. "Mechanical behavior of lightweight soil reinforced with waste fishing net", Geotextiles and Geomembranes, 26, pp. 512-518 (2008).

22. Babu, G.S. and Chouksey, S.K.. "Stress-strain response of plastic waste mixed soil", Waste Management, 31, pp. 481-488 (2011). 
23. Muntohar, A.S., Widianti, A., Hartono, E., and Diana, W. "Engineering properties of silty soil stabilized with lime and rice rusk ash and reinforced with waste plastic fiber", Journal of Materials in Civil Engineering (ASCE), 25(9), pp. 1260-1270 (2013).

24. ASTM D-422, Standard Test Method for Particle-size Analysis of Soils, Annual Book of ASTM Standards, USA (2007).

25. ASTM D-2487, Standard Practice for Classification of Soils for Engineering Purposes (Unified Soil Classification System), Annual Book of ASTM Standards, USA (2017).

26. ASTM D-854, Standard Test Methods for Specific Gravity of Soil Solids by Water Pycnometer, Annual Book of ASTM Standards, USA (2014).

27. ASTM D-4254, Standard Test Methods For Minimum Index Density and Unit Weight of Soils and Calculation of Relative Density, Annual Book of ASTM Standards, USA (2016).

28. ASTM D-4253, Standard Test Methods For Maximum Index Density and Unit Weight of Soils Using a Vibratory Table, Annual Book of ASTM Standards, USA (2016).

29. Noorzad, R. and Amini, P.F. "Liquefaction resistance of Babolsar sand reinforced with randomly distributed fibers under cyclic loading", Soil Dynamics and Earthquake Engineering, 66, pp. 281-292 (2014).

30. Baldi, G., Hight, D.W., and Thomas, G.E. "State-ofthe-art paper: a reevaluation of conventional triaxial test methods", In Advanced Triaxial Testing of Soil and Rock, ASTM International (1988).

31. Lambe, T.W. and Whitman, R.V., Soil Mechanics SI Version, John Wiley and Sons, New York (2008).

32. Haeri, S.M., Noorzad, R., and Oskoorouchi, A.M. "Effect of geotextile reinforcement on the mechanical behavior of sand", Geotextiles and Geomembranes, 18(6), pp. 385-402 (2000).

33. Noorzad, R. and Raveshi, M. "Mechanical behavior of waste tire crumbs-sand mixtures determined by triaxial tests", Geotechnical and Geological Engineering, 35(4), pp. 1793-1802 (2017).

34. Head, K.H., Manual of Soil Laboratory Testing, 3, Pentech Press, London (1986).

35. Baldi, G. and Nova, R. "Membrane penetration effects in triaxial testing", Journal of Geotechnical engineering, 110(3), pp. 403-420 (1984).

36. Anagnostopoulos, C.A., Papaliangas, T.T., Konstantinidis, D., and Patronis, C. "Shear strength of sands reinforced with polypropylene fibers", Geotechnical and Geological Engineering, 31(2), pp. 401-423 (2013).

37. Mirzababaei, M., Arulrajah, A., Horpibulsuk, S., and Aldava, M. "Shear strength of a fibre-reinforced clay at large shear displacement when subjected to different stress histories", Geotextiles and Geomembranes, 45(5), pp. 422-429 (2017).
38. Bishop, A.W. "Shear strength parameters for undisturbed and remoulded soil specimens", In Proceedings of the Roscoe Memorial Symposium, Cambridge University, Cambridge, Weight, pp. 29-31 (1971).

39. Ta'negonbadi, B. and Noorzad, R. "Stabilization of clayey soil using lignosulfonate", Transportation Geotechnics, 12, pp. 45-55 (2017).

40. Duncan, J.M. and Dunlop, P. "The significance of cap and base restraint", Journal of the Soil Mechanics and Foundations Division, 94(1), pp. 271-290 (1968).

41. Dutta, R.K. and Venkatappa Rao, G. "Engineering properties of sand reinforced with strips from waste plastic", In Proceedings of the International Conference on Geotechnical Engineering, Sharjah, UAE, pp. 186-193 (2004).

\section{Biographies}

Bahram Ta'negonbadi was born in Gonbade Kavoos, Golestan, Iran in 1989. He received his BSc degree in Civil Engineering from Ferdowsi University of Mashhad in 2011, MSc degree in Geotechnical Engineering from Sharif University of Technology in 2013, and $\mathrm{PhD}$ degree in Geotechnical Engineering from Babol Noshirvani University of Technology, Bbaol, Iran in 2018. His main areas of research interest include soil stabilization, soil improvement, underground spaces (tunnels) under dynamic loadings, soil-structure interaction, earth dams, and geotechnical earthquake engineering.

Reza Noorzad was born in Nour, Mazandaran, Iran in 1964. He received both his BSc and MSc degrees in Civil Engineering and Geotechnical Engineering from Tehran University, Tehran, Iran in 1990 and 1994, respectively, and his $\mathrm{PhD}$ degree in Geotechnical Engineering from Sharif University of Technology, Tehran, Iran in 2000. He is currently an Associate Professor in the Department of Civil Engineering at Babol Noshirvani University of Technology. From 2004 to 2007, he was the Head of Central Library and Documentation Centre at Mazandaran University. His research interests include soil improvement, reinforced soil, earth dams, marine geotechnics, and geotechnical earthquake engineering.

Pardis Shakery was born in Babol, Mazandaran, Iran in 1987. She received her BSc degree in Civil Engineering from Tabari Institute of Higher Education in 2010 and MSc degree in Geotechnical Engineering from Babol Noshirvani University of Technology in 2014. Her research interests include soil improvement and soil reinforcement. 